\title{
What happened to alternative lower-secondary education in Mauritius? : The extended programme as a case of misguided curriculum, unfair assessment, and social injustice
}

\author{
Nitin Rughoonauth \\ n.rughoonauth@uom.ac.mu \\ Department of Physics, Faculty of Science, University of Mauritius
}

\section{Abstract}

The recent Nine-Year Continuous Basic Education (NYCBE) reform has brought about a dramatic change in the provision of alternative lower-secondary education in the Republic of Mauritius. Whereas the previous prevocational education (PVE) programme allowed educators to make use of an aims-based curriculum to respond to the learning profile of children marginalised within the primary education system by formatively catering for their holistic development in an inclusive and integrated manner and preparing them for vocational pathways, the new extended programme (EP) proposes to engage those same learners with a knowledge-based curriculum that focuses heavily on subject learning and high-stakes examinations. Our aim in this article is to examine, through the lens of social justice, the aims, objectives and expectations of the two alternative education programmes, and elaborate, by looking at aspects of curriculum, pedagogy and assessment, on how the EP ends up being a fundamentally flawed and poorly implemented programme that undermines the development and potential for human flourishing of the learners concerned. Implications for educators involved in the programme will also be touched upon. 


\section{Introduction}

The education system of the Republic of Mauritius has, since 2015, been undergoing a major reform called the 'Nine-Year Continuous Basic Education' (NYCBE). This is "in line with the international commitment to the United Nations Sustainable Development Goal (SDG) 4 on Education" (MoEHRTESR, 2016a: 5), which is to "ensure inclusive and equitable quality education and promote lifelong learning opportunities for all" (UNGA, 2015). Hence, in the name of equity, the NYCBE makes provision for all students of the Republic to complete nine years of basic education, that is six years of primary followed by three years of lower secondary education. In this article, we use the lens of social justice to focus on how alternative provision of lower secondary education to those not successful in the national examinations at the end of 6 years of primary schooling has been transformed.

Prior to 2017, all Grade 6 (end-of-primary) students took part in high-stakes examinations leading to the Certificate of Primary Education (CPE), and those (about 30$40 \%$ of examinees (HRDC, 2007)) not achieving the required grades to continue with mainstream education at lower secondary level would integrate the alternative prevocational education (PVE) programme (MoEHR, 2011) which would provide a pathway to either technical and vocational education and training (TVET) or postsecondary education. With an estimated $28 \%$ of PVE students failing to complete the programme (MoEHRTESR, 2016a: 7) and given that it was necessary to significantly raise the level and improve the relevance of learning outcomes to facilitate access to quality TVET, the PVE programme was gradually phased out to give way to an alternative Extended Programme (EP) that was introduced in the NYCBE reform to allow those 
students who have not achieved the required grades in the new Primary School Achievement Certificate (PSAC) examinations at the end of Grade 6, to complete their basic education (the PSAC effectively replaced the CPE).

This article focuses on issues of social justice and fairness, in the context of alternative education provision, related to the change from a mostly aims-based (Reiss and White, 2013) PVE curriculum (which emphasises the needs and wants of students) to one which is predominantly knowledge-based (Young, 2013) for the EP (which focuses on the learning of required particular subjects), and from a framework of mostly school-based modes of continuous assessment in PVE to one with high-stakes examinations at the end of the EP. We will first look at how the PVE curriculum was meant "to make up for the academic deficit built up during the years of primary schooling and to enable skills development for further vocational training" (MoEHR, 2011: 2). The aims of PVE in terms of additional schooling and preparation guided the interdisciplinary approach adopted in designing the PVE curriculum. In contrast, the EP curriculum is effectively the same as the knowledge-based curriculum for mainstream Grades 7-9, but adapted over a fouryear period.

Finally, we will look at the assessment frameworks of both alternative education programmes. It was decided that EP students will, as from 2021, sit, at the end of the four-year cycle, for the same high-stakes examinations as the Regular Programme (RP) or mainstream students at the end of Grade 9, leading to the National Certificate of Education (NCE) (MES, 2018). However, it is more and more likely, given evidence gathered from the first two years of running the EP (MIE, 2020) and from past experience in PVE, that these EP students will not be able to complete the curriculum 
they are meant to cover over four years. That they will have to prepare to take the same examination papers as those coming from the mainstream is a deeply misguided and unfair decision that compromises the main purposes and validity of those examinations.

\section{Pre-vocational education (PVE) and social justice}

PVE was introduced in Mauritius in the 1990s as a three-year post-primary alternative education pathway for Grade 6 pupils who were not successful at the CPE examinations. Those children, half of whom came from disadvantaged socio-economic backgrounds (where parents have only completed primary education (MIE, 2020)) and who had faced significant learning difficulties and health issues, would have otherwise dropped out of school and been further marginalised. With the advent, in 2004, of compulsory schooling until the age of 16 , PVE was restructured to provide a more generic base of academic skills combined with vocational skills. More importantly, a PVE curriculum was developed with a set of educational aims (see MIE (2009: 184)) as guiding principles, and was also based on goals laid out in the policy document 'Empowering the Nation's Children - Towards a Quality Curriculum' (MoEHR, 2006a), as well as on learning outcomes defined in the National Curriculum Framework - Secondary (NCFS) (MIE, 2009). Reiss and White (2014) argue that, contrary to Michael Young's idea (see Young (2016: 76)) that school subjects constitute the basis of "powerful knowledge", curricula in fact should be designed with aims considered first. The aims-based PVE curriculum had a fundamental advantage, in that it addressed the needs and wants of those students from both during their schooling and once they had completed the programme.

The PVE programme consisted of four core learning domains (LDs): (1) Communication Skills; (2) Numeracy and Problem-Solving Skills; (3) Life Skills; and (4) Livelihood and 
Trade Skills. These were to be taught using an interdisciplinary, process-based and project-based pedagogical approach "to offer opportunities for students to learn in authentic and collaborative contexts" (MIE, 200: 195), which is reminiscent of Vygotsky's social theory of learning (Vygotsky, 1962). All these aspects of a curriculum based on clearly defined and well-motivated learner-centred objectives that promoted and guided the development of skills essential to the learner's fulfilment and perceived sense of autonomy would allow the learner to aim for a life that would be personally flourishing, and that would collectively enable such learners to help each other to similarly lead flourishing lives in "preparation for work" (Reiss and White, 2014: 76).

PVE took place in the same secondary institutions as mainstream academic education, all "based on the philosophy of an inclusive education with all students enjoying the same school facilities. This approach [...] was thought to allow the children in the PVE stream to gain self-esteem and self-confidence without any negative branding" (MoEHR, 2011: 2). Access to the same infrastructural benefits and the possibility to develop social relationships were meant to indicate to those students that they were being cared about in a tangible way, although in some cases those same students could be exposed to forms of cultural injustice (Fraser, 1997; 2009), for instance a reinforced perception that they were inferior to mainstream students. However, the same-school policy, as a means for achieving socially just outcomes for these otherwise marginalised students, characterised a form of affective justice (Lynch, 2012) since they were being recognised culturally and socio-economically by their peers. 


\section{Prevok-BEK}

In 2005, the Mauritian Bureau d'éducation catholique (BEC) (Bureau of Catholic Education) introduced a literacy-in-Mauritian-Creole programme called the Prevok-BEK - the first vernacular-based curriculum in Mauritius - to the PVE framework, with Kreol Morisien $^{1}(\mathrm{KM}$, Mauritian Creole) being used as both a language of instruction and a language subject. This programme was first implemented in BEC-run secondary schools and catered for about $15 \%$ of PEV students coming from the most disadvantaged backgrounds and who struggled in learning because the medium used was English, instead of KM or French (Chung, 2013). The main objectives of using KM were to “enhance students' self-esteem, ability and confidence; rekindle students' interests and motivation in learning; improve student-teacher relationships; and activate students' participation" (CS, 2012: 132). A language-adapted curriculum and pedagogy that valued and built upon the knowledge and cultural backgrounds of the students were crucial for achieving socially just outcomes for the marginalised young people. Prevok-BEK "broke taboos about the status of KM" (Chung, 2013: 132; Rajah-Carrim, 2007) by gradually influencing public opinion and informing government policy decisions (see AnkiahGangadeen and Nadal, 2018). In 2007, after three years of the programme and positive results from the first cohort (Chung, 2011), the initiative was nationally adopted and recommended as good practice in the list of recommendations in the National Human Rights Report (NHRC Mauritius, 2007: para. 35).

\footnotetext{
${ }^{1} \mathrm{Kreol}$ Morisien is the French-based creole language which is the vernacular in Mauritius.
} 


\section{Four-year PVE and certification}

In 2011, PVE was extended to a four-year programme in line with the objective of providing for both flexibility of access between programmes and institutions, and to facilitate transition to vocational education and/or the labour market through certification. The PVE certificate enabled the learner to either opt for vocational education, or reintegrate an academic stream, or become functional and employable in any sector. The possibility for PVE graduates to eventually join the academic mainstream was crucial since it provided them with the opportunity to access higher education. As Mills et al. (2015) point out, typical concerns raised about the alternative education sector often refer to it as being a "dumping ground for students 'unwanted' by the education system" (p. 103) (see also Kim, 2011; Kim and Taylor, 2008; Mills et al., 2013; Smyth et al., 2013) such that increased use of alternative education programmes for younger and younger students can lead to them being separated from the mainstream and its benefits (De Jong and Griffiths, 2006). Furthermore, it was necessary to dispel what Thomson and Russell (2007) suggest as a tendency to assume that what all young people in alternative learning environments "need and want is vocational options" ( $p$. viii).

The four-year PVE programme allowed educators to cater for the holistic development of the learners. With PVE students in the $3^{\text {rd }}$ and $4^{\text {th }}$ years of the programme spending half of their school hours pursuing technical training out of school, this meant that there was an emphasis, in the later years at least, on experiential (instead of fact- or contentdriven) learning, and the use of integrated and inclusive approaches, which Mills et al. (2015) would contend as being "fundamental to the achievement of contributive justice, and hence social justice" (p. 112). Incidentally, the students were engaged in learning 
that did not involve repeating or reinforcing their prior experiences of failure (Hayes, 2012).

\section{Basic education for all - The Extended Programme as alternative provision}

The need for a nine-year cycle of free basic education catering for all children of the Republic, together with the decision, in line with SDG 4 (UNGA, 2015), that all learners should be taught the same curriculum, meant that PVE had to be abandoned. A new alternative lower secondary pathway, based on the National Curriculum Framework Grades 7,8 \& 9 (MIE, 2017), would be made available to children who could not attain the minimum required grades in the PSAC examinations at the end of Grade 6. This was introduced in 2018 as the four-year EP, whereby "all learners will be given opportunities to achieve the standards of knowledge, understanding and skills at the end of each Grade, as prescribed in the core curriculum for Grades 7 - 9" (MIE, 2017: 22).

\section{EP as an accelerated programme, and incapacity to address learning deficits}

The EP thus presents itself as the only available alternative lower secondary education, where students are expected to benefit from a "differentiated pedagogy, appropriate learning materials, conducive learning environment and adapted assessment so as to achieve the agreed learning objectives" (MIE, 2017: 5). Year 1 (Grade 7) of the EP is aimed at reconnecting the learner with school and providing remedial education and "learning support to address learning difficulties" (MIE, 2017: 21). However, let us consider, say, the Mathematics "skills/competencies" in the EP Grades $7 \& 8$ Progress Book (MIE, 2019a: 25-29) and Grades 9 \& 9+ Progress Book (MIE, 2019b: 31-48), which are "meant to systematically record the progress of students" (p. 3) in Year 1 \& Year 2 
(Grade 8), and Year 3 (Grade 9) \& Year 4 (Grade 9+) of the EP, respectively, "according to curriculum expectations" (p. 4). If we compare these with the "specific learning outcomes" laid out in the "Mathematics Teaching \& Learning Syllabus (TLS) Grades 1 6' (MIE, 2015: 9-17) and the TLS Grades 7 - 9 (MIE, 2019c: 45-57), we find that the EP student actually ends up spending Years 1 and 2 reviewing the primary level mathematics (although there is now evidence (MIE, 2020) that those two years are not sufficient for EP students to compensate for learning deficiencies accumulated at primary level), and Years 3 and 4 covering the three years of lower secondary level mathematics. This situation is the same for all other subjects.

Thus, the EP students, who were meant to take more time than the RP students to study the lower secondary curriculum, are effectively spending less time doing so! Given that these EP students have a profile similar to those of the PVE (MOEHRTESR, 2016b), it is very likely that they will progress slowly across the curriculum and will only be able to cover part of it. Indeed, it was found in a mid-term evaluation of the EP (MIE, 2020) that $70 \%$ of Grade 8 EP students were able to answer less than half of the examination questions set to measure competencies that they should have acquired in the upper primary years. With only $40 \%$ of teaching time dedicated to literacy and numeracy in Grades 7-8, this has proved to be insufficient in addressing learning deficits. Furthermore, the curriculum was rated as not being adequately adapted to EP students by $68 \%$ of teachers and $50 \%$ of facilitators (PVE educators who have been retrained to service the EP), and a significant number of administrators stated that the EP should have a technical dimension and be mainly based on workshop- or activity-learning, with the students ultimately being redirected towards TVET. This brings out an inherent 
tension between policy decisions focused on inclusion and equity through the same curriculum and students' inclination towards practical-based subjects.

\section{Other shortcomings in EP implementation}

The shortcomings in the curriculum and in its delivery (which is limited to teachercentred approaches and is, in practice, not tailored to individual students' needs) are exacerbated by an infrastructure that is not always well adapted to EP functions. In some schools, for instance, EP classrooms are separate from other amenities and have no access to electricity, thus having the unintended consequence of creating segregation between EP and RP students. A third of schools sampled in the mid-term evaluation showed average EP class sizes to be larger than 20, indicating that the EP policy of small student-teacher ratio to help create the proper learning environment is not being followed in all schools, thus resulting in lack of individualised attention to students. Many teachers also find class management to be difficult. Furthermore, the selection of teachers and facilitators to service the EP was top-down and made without consulting their interests, thus limiting their buy-in to the programme, constituting an obstacle to effective implementation. From the school personnel surveyed, $45 \%$ of the teachers reported that they did not feel motivated by their work in the EP, and $65 \%$ believed that it was not professionally rewarding, with many of them stating that they were not initially prepared or trained to work in the EP. Half of the facilitators stated that their role was not well-defined, and that they occupied a low-status role within the school hierarchy, and were often even expected to carry out menial tasks outside their terms of reference. This amounts to a form of prejudice that may lead some educators to taking a less active role in leading, learning, and reflecting upon their relationship with 
their practice and the social context in which the practice is situated (Giroux, 1992; Meirink et al., 2009).

\section{Curricular (in)justice and drop out}

Whereas the underlying philosophy of the EP is "inclusiveness, equity and quality" (MoEHRTESR, 2017: 3), and is to "provide opportunities and necessary support for all students to achieve the essential outcomes of the basic educational cycle", and to be "ready for upper secondary/vocational education" (p. 3), it appears that this alternative education programme actually fails to support socially just education for all learners. Although the NYCBE curriculum is meant to be "inclusive" (MIE, 2017: 22), it seems to fall short of ensuring that there is "parity of participation" (Mills et al., 2015: 102) of EP learners, and compromises "curricular justice" (Connell, 1993: 19). Connell identifies three principles which, taken together, may constitute a conceptualisation of curricular justice: (1) participation and common schooling - "ungraded and co-operative learning practices in respect of the common curriculum"; (2) the interests of the 'least favoured' groups in society - i.e. "advantaging the least advantaged" (see also Rawls, 1971); and (3) the historical production of equality - the "tendency of an educational strategy to produce more equality in the whole set of social relations to which the educational system is linked" (Connell, 1992: 138-141). The way the EP is being delivered violates these principles through unadapted teaching and learning practices, unfair pacing of curriculum coverage, and a tendency to increase inequality. One objection usually raised against Young's "knowledge-based approach" to curriculum is that it "almost certainly increases the proportion of failing pupils and encourages more disaffection and drop out" (Young, 2013: 112). Such a point of disapproval could equally be raised in the case of EP since it is likely, given that 3 years of curriculum have been squeezed into 2 years 
of EP, that those students will lose confidence, disengage and drop out during the last 2 years of the programme, if not earlier. In fact, of the 9796 EP students starting in three Grade 7 cohorts over the period 2018-2020, 9221 were still enrolled in 2020, which represents a drop of approximately $6 \%$ in the number of EP students over the 3 years, with most students dropping out at the end of Grade 8 (SM, 2020).

\section{Lack of mobility and symbolic violence}

Access of EP students to the lower secondary curriculum is further limited by the fact that the EP allows for mobility, subject to the parents' choice, of students with learning difficulties from the RP to the extended track (see MIE, 2017: 21), but not the other way around (it was found (MIE, 2020) that $2 \%$ of EP students were enrolled in the programme partly because some parents chose to secure a place for their child, who was a priori eligible to join the RP, in one of the 'high-status' schools). At the time of writing, there is no evaluation mechanism that could be embedded into school-level processes to allow demonstrably high-performing EP students to accede to RP classes (MIE, 2020). Some policymakers (e.g. P.R. Ramlugun, then Senior Chief Executive of the Mauritian Ministry of Education, 2018, personal communication) believe, given that the EP and RP are dissimilar in terms of pace, pedagogy and potentially extent of curriculum coverage, and that parents of EP students are risk-averse and relatively disengaged from their children's education to want them to join the RP (see e.g. Heineck and Riphahn (2009) and Wölfel and Heineck (2012) for tracking in Germany), that most EP students would struggle to progress enough to integrate the regular track. This lack of mobility further marginalises the EP student by depriving mobility to those who can actually progress in their learning. From a Bourdieusian perspective, that this injustice has not been addressed leads to a form of "symbolic violence" (Bourdieu, 1977: 237) whereby those 
involved in the two programmes are complicit in a power differential that denies the EP student the possibility of gaining access to knowledge that would provide "reliable explanations or new ways of thinking about the world" (Young, 2016: 110). Given how the strong relationship between educational achievement and social mobility (OECD, 2012) could lead to a reproduction of existing social patterns, one would be inclined to agree with Fraser $(1997 ; 2009)$ when she argues that all such aspects of injustice have to be attended to in order to achieve a socially just society.

\section{Challenges of a knowledge-based curriculum}

Although provisions are made to offer EP students a differentiated curriculum, it remains that the Grades $7-9$ curriculum is heavily knowledge-based, since it is when students from both programmes start to learn more specialised subjects. This seems to correspond to Young's idea that "the primary purpose of education is for students to gain access to different specialist fields of knowledge" (Young, 2016: 109). However, instead of four LDs like in the PVE curriculum, the number of "learning areas" (LAs) the EP student will study is relatively much bigger. There are nine such core LAs (MIE, 2017: 18), all of which are examinable at the end of Grade 9+ (MES, 2018): (1) Languages; (2) Mathematics; (3) Science; (4) Technology Studies; (5) Social \& Modern Studies; (6) Business \& Entrepreneurship Education; (7) Physical Education; The Arts; (8) Information \& Communication Technology; and (9) Life Skills \& Values. This represents a heavy learning load for an EP student who has only 2 years to cover the Grades 7-9 curriculum. Furthermore, a LA like Business \& Entrepreneurship Education (BEE) is barely covered in Years 1 and 2 of the EP, and it is essentially a new LA to EP students by the time they start Year 3. To expect that such students would be able to learn and master subjects such as Accounting, Business \& Entrepreneurship, and Economics, all of which are part 
of BEE, over a reduced period would be to show great prejudice towards them. Typical EP students not only endure academic difficulties, but they also struggle to cope with issues such as social problems, lack of motivation, and health problems, among others. This admittedly burdensome knowledge-based curriculum appears to present the EP student with a significant challenge that is unjust.

\section{Powerful knowledge and contributive injustice}

As much as it is important that care be exercised in the provision of alternative education to ensure that EP students do not receive a watered-down curriculum that damages their sense of self-respect, it is equally crucial to ensure that these same students are not prescribed an overly ambitious curriculum that appears to serve no purpose, provides little by way of satisfaction, and serves to demoralise them, which would "not only represent an affective injustice, a lack of care, but also constitute a contributive injustice" (Mills et al., 2015: 104). One of the goals of the NYCBE curriculum is to "promote an inclusive environment that will enable all learners to experience quality education, realise their full potential and achieve excellence" (MIE, 2018: 16). In that respect, it would seem that gaining access to what Young (2016) refers to as "powerful knowledge" would allow EP students to succeed later in life. Young understands powerful knowledge as being context-independent, as opposed to context-dependent knowledge which "is developed in the course of solving specific problems in everyday life" (p. 111). However, EP students tend to come from low socio-economic backgrounds, and are more likely to be at a disadvantage in engaging with context-independent knowledge since they are more "constrained by the material exigencies in life" (Young, 2016: 111). Young writes that "the success of pupils is highly dependent on the culture that they bring to school" (p. 111), but I would argue that it is equally important that the 
school provides the right environment for the culture to find meaning and emancipate itself without the students having to experience forms of cultural injustice. Expecting EP students, who are already educationally marginalised, to consolidate their primary level knowledge and understanding and to eventually engage with a more advanced and elaborate curriculum, all within four years, would be misrecognising their struggles and potential. These students would be "forced to suppress their own cultural ways of being and communicating to the (often hostile) norms of the dominant culture" (Mills et al., 2015: 101), here represented by the knowledge-based curriculum of the powerful.

\section{Assessment and fairness}

\section{PVE and continuous assessments}

We finally turn to the issue of how the changing landscape of assessment in lower secondary alternative education programmes has led to a situation where high-stakes examinations will further exacerbate the situation with the EP. In the four-year PVE programme, the learning process and progress of students were closely monitored by teachers as from Year 1 using continuous assessment tasks provided in manuals prepared by the Mauritius Institute of Education (MIE). While mainstream students were assessed at the end of Grade 9 through an externally set (by the Mauritius Examinations Syndicate (MES)) but school-administered low-stakes summative national assessment (see MES, 2019), PVE students were assessed for certification purposes only in Years 3 and 4 through (i) continuous school-based assessments consisting of portfolios \& personal development plans (40\%) and practical tests $(40 \%)$, and (ii) summatively through national written examinations (20\%) set by the MES (MoEHR, 2011), where the percentages denote the contributions of each type of evaluation to the final marks. In 
addition, a modular approach, "with due attention to practical and applied skills" was adopted in PVE to "cater for the different range of abilities, and to allow for more flexibility, especially for those who have failed with the traditional examination structure" (MoEHR, 2011: 11).

To further assist those students with language difficulties, the Prevok-BEK programme introduced an innovative bilingual English/Kreol Morisien mode of assessment in 2008 (Chung, 2013). Completion of the 4 years of alternative schooling led to a certification formally recognised on the National Qualifications Framework (NQF), which enabled the PVE graduate to opt for either vocational education, or reintegrate the academic mainstream, or "become functional and employable in any sector" (MoEHR, 2011: 11). This provided a statement of achievement in each LD to allow prospective employers to identify key desirable skills in the learner, thus making it easier to testify to the learner's knowledge and skills on the job market. Thus, the PVE assessment and certification framework ensured that the students could be formatively assessed, so as to be properly supported in their learning, and certified without them having to endure stressing situations and potential failure experiences in taking high-stakes examinations.

\section{EP and the NCE}

On the other hand, EP students, whose learning progression is monitored formatively using a set of tools that includes the 'Secondary School Readiness' assessment (carried out at Grade 7 to profile each learner) (MIE, 2018), the 'Individual Education Plan' (designed for learners with special educational needs) (MoEHR, 2006b), the 'Differentiated Education Plan' (for learners needing differentiated pedagogical support), as well as the Progress Books mentioned earlier, are ultimately meant to take 
the same examinations at the end of their four years of schooling as RP students. These examinations mark the end of the basic education cycle, and lead to the NCE. The NCE serves several purposes (MES, 2018: 5150): to assess and certify levels of learning attained in the different LAs; and to provide evidence for promotion to Grade 10 , the orientation of students in their subject choices and education pathways beyond Grade 9, and admission to 'academies', which are "selective specialist institutions of academic excellence" (MoEHRTESR, 2016a: 36). Each LA is assessed through a written examination consisting of one single paper (MES, 2020a) set for students from both programmes. Because the examinations are meant to assess and discriminate (for the purpose of admission to academies) among RP students, the assessments cover the whole of the Grades 7 - 9 curriculum. That EP students will be assessed in these high-stakes examinations has several serious implications for the people involved in the programme.

Because it is very likely that EP teachers will not be able to cover the whole Grades 7 9 curriculum during Years 3 and 4, EP students will end up taking examinations that feature items which test concepts they may not have learned, which is unfair and compromises the assessment's purpose and validity (AERA, APA and NCME, 2014). Indeed, EP students and teachers surveyed in the mid-term evaluation of the EP (MIE, 2020) reported feeling anxious about the possibility of academic failure. The numerous issues mentioned above have the effect that the school personnel have low expectations about not only their agency as professionals (e.g. see Hurreeram, 2019; Kelchtermans, 2009) but also regarding the performance of EP students, with $77 \%$ of administrators expecting fewer than $30 \%$ of EP students to achieve the NCE in Grade 9+, and none of them expecting more than half of the students to pass. Facilitators generally show slightly higher expectations, while teachers' opinions occupy the middle ground 
between those of administrators and of facilitators (MIE, 2020). More generally, that same study revealed that stakeholders tend to perceive the NCE as an obstacle rather than a tool to inform policymakers of the extent to which the EP has been successful at improving learning outcomes of those learners at the end of the four-year cycle. Also, the use of the NCE calls into question the viability of using an adapted EP curriculum, with many EP educators expressing their concern about the mismatch that exists between the new curricular provisions and learner profile (Hurreeram, 2019). Although they may be perceived as extrinsic motivators to learning (Pintrich and Schunk, 2002), the high-stakes examinations could nevertheless demoralise EP students and "undermine their intrinsic motivation" (Kellaghan et al., 1996), leading many of them to disengage and drop out. Furthermore, the need and pressure to obtain the NCE may lead to an increase in the dropout rate (Amrein and Berliner, 2003; Jacob, 2001) since students who are retained in the EP are significantly more likely to drop out (Goldschmidt and Wang, 1999).

There are also unintended effects on teachers and school administrators as they could be held accountable (Buchanan, 2015) for poor performance of EP students (Reese et al., 2004), which would be improper and unfair (Popham, 1999; 2000) since the EP is inherently problematic. EP teacher beliefs about the invalidity of the examinations "can generate feelings of dissonance and alienation" (Smith, 1991), with many of them developing negative attitudes towards their profession leading to "lower teacher morale, less enjoyment in their job, and an increase in teacher attrition" (Jones, 2007: 74) (see also DeBard and Kubow, 2002; Jones and Egley, 2004). Curriculum instruction and highstakes exam preparation would compete for time, possibly leading to a reduction of teaching time, a narrowing of the curriculum, a reduction to teachers' ability to adapt 
and create (Jones, 2007), with some teachers even choosing to spend less attention on those students who are not likely to pass the examinations (Booher-Jennings, 2006). Thus, there are potentially a number of issues, most prominently that of fairness, in having the EP students take the same high-stakes examinations as RP students.

\section{Conclusion}

In this article, we have argued that, given the socio-economic and ability profile of the child entering those alternative modes of education, the aims-based PVE curriculum together with continuous school-based assessments would have provided more opportunities for the child to acquire the knowledge, skills and competencies necessary to eventually lead a life that is "personally flourishing" (Reiss and White, 2014: 76). Furthermore, the PVE curriculum would have allowed the child to develop the right attitude "to contribute positively in a challenging social context" (MIE, 2009: 184), thus making it possible for the child to help others to personally flourish. We have also considered the importance of 'affective' (Lynch, 2012) and 'contributive' (Sayer, 2009; 2011) aspects of justice, and how these are "central to the achievement of social justice for the young people attending alternative education" (Mills et al., 2015: 100).

Although the NYCBE is aimed at providing access to quality basic education to all students, where participation in the EP may be "the only opportunity that disadvantaged children may have to acquire powerful knowledge" and "move [...] beyond their local and particular circumstances" (Young, 2016: 111), the key curriculum questions concerned with how knowledge is paced and assessed in this programme show that there are serious issues of social justice and fairness, with numerous detrimental implications for students and teachers, that need to be addressed so that the EP could 
be considered a viable alternative education pathway. Until then, children in alternative education will continue to suffer from various forms of injustice, leading to them being further marginalised.

\section{Acknowledgement}

The author is grateful to Dr Emma Jones of UCL Institute of Education for feedback on an earlier draft of this article.

\section{Financial Support}

The author was supported by a UK Foreign, Commonwealth and Development Office Chevening scholarship. 


\section{References}

Ankiah-Gangadeen A and Nadal P (2020) Relocating social justice in the policy-pedagogyresearch nexus: Insights from the Mauritian language-in-education policy. In: Wolhuter C (ed) Education Studies in South Africa: The Quest for Relevance, Rigour and Restructuring. AOSIS: Cape Town: AOSIS, pp. 225-244.

American Educational Research Association (AERA), American Psychological Association (APA) and National Council on Measurement in Education (NCME) (2014) Standards for educational and psychological testing. Washington, DC: AERA.

Amrein, AL and Berliner DC (2003) The effects of high-stakes testing on students' motivation and learning. Educational Leadership 60(5): 32-38.

Booher-Jennings J (2006) Rationing education in an era of accountability. Phi Delta Kappan 87(10): 756-761.

Bourdieu P (1977) Outline of a Theory of Practice. Duke University Press.

Buchanan R (2015) Teacher identity and agency in an era of accountability. Teachers and Teaching 21(6): 700-719.

Chung G (2011) Survey on the situation of prevocational students at point of entry and after three years in the Prevok-BEK program. Mauritius: Bureau of Catholic Education.

Chung G (2013) Leadership for Inclusion and Policy-making: Initiatives of the Catholic Education Sector in Mauritius for the Preferential Option for the Poor. In: 6th International Conference on Catholic Educational Leadership, Centre for Creative and Authentic Leadership, Australian Catholic University, Australia, 12-14 August 2013.

Commonwealth Secretariat (CS) (2012) Prevok-BEK: literacy and numeracy within national pre-vocational education. In: Commonwealth Education Partnerships 2012/2013.

Connell RW (1992) Citizenship, Social Justice and Curriculum. International Studies in Sociology of Education 2(2): 133-146.

Connell RW (1993) Schools and social justice. Philadelphia: Temple University Press.

DeBard R and Kubow PK (2002) From compliance to commitment: The need for constituent discourse in implementing testing policy. Educational Policy 16(3): 387-405.

De Jong T and Griffiths C (2006) The role of alternative education programs in meeting the needs of adolescent students with challenging behaviour: Characteristics of best practice. Australian Journal of Guidance \& Counselling 16(1): 29-40.

Fraser N (1997) Justice interruptus: Critical reflections on the 'postsocialist' condition. New York: Routledge.

Fraser N (2009) Scales of justice: Reimagining political space in a globalizing world. New York: Columbia University Press.

Giroux HA (1992) Border crossings: cultural workers and the politics of education. London: Routledge. 
Goldschmidt P and Wang J (1999) When can schools affect dropout behavior? A longitudinal multilevel analysis. American Educational Research Journal 36(4): 715-738.

Hayes D (2012) Re-engaging marginalised young people in learning: The contribution of informal learning and community-based collaborations. Journal of Education Policy 27(5): 641-653.

Heineck G and Riphahn RT (2009) Intergenerational transmission of educational attainment in Germany: The last five decades. Jahrbücher für Nationalökonomie und Statistik 229: 36-60.

Human Resource Development Council (HRDC) (2007) Chapter 2: Education and Training in Mauritius. National Human Resource Development Plan.

Hurreeram N (2019) Prevocational educators' construction of agency in negotiating their professional development amidst dilemmas of pedagogical practices. Doctoral Thesis, University of Brighton, UK.

Jacob BA (2001) Getting tough? The impact of high school graduation exams. Education Evaluation and Policy Analysis 23(2): 99-121.

Jones BD (2007) The Unintended Outcomes of High-Stakes Testing. Journal of Applied School Psychology 23(2): 65-86.

Jones BD \& Egley RJ (2004) Voices from the frontlines: Teachers' perceptions of high-stakes testing. Education Policy Analysis Archives 12: 39.

Kelchtermans G (2009) Who I am in how I teach is the message: Self-understanding, vulnerability and reflection. Teachers and Teaching: theory and practice 15(2): 257-272.

Kellaghan T, Madaus GF and Raczek A (1996) The use of external examinations to improve student motivation. Washington, D.C.: American Educational Research Association.

Kim J-H (2011) Narrative inquiry into (re)imagining alternative schools: A case study of Kevin Gonzales. International Journal of Qualitative Studies in Education 24(1): 77-96.

Kim, J-H and Taylor, KA (2008) Rethinking alternative education to break the cycle of educational inequality and inequity. The Journal of Educational Research 101(4): 207219.

Lynch K (2012) Affective equality as a key issue of justice: A comment on Fraser's 3dimensional framework. Social Justice Series 12(3): 45-64.

Mauritius Examinations Syndicate (MES) (2018) Annual Programme for the National Certificate of Education (NCE) Assessment for 2020. The Government Gazette of Mauritius 123: 5135-5174.

Mauritius Examinations Syndicate (MES) (2019) National Assessment at Grade 9, Handbook for Schools.

Mauritius Examinations Syndicate (MES) (2020a) National Certificate of Education (NCE) Specimen Papers.

Mauritius Examinations Syndicate (MES) (2020b) National Certificate of Education Mathematics Specimen Paper for first assessment in October 2020. 
Mauritius Institute of Education (MIE) (2009) National Curriculum Framework - Secondary.

Mauritius Institute of Education (MIE) (2015) Mathematics Teaching and Learning Syllabus Grades $1-6$.

Mauritius Institute of Education (MIE) (2017) National Curriculum Framework Grades 7, 8 \& 9.

Mauritius Institute of Education (MIE) (2018) Secondary School Readiness.

Mauritius Institute of Education (MIE) (2019a) Extended Programme Grades 7 \& 8 Progress Book.

Mauritius Institute of Education (MIE) (2019b) Extended Programme Grades 9 \& 9+ Progress Book.

Mauritius Institute of Education (MIE) (2019c) National Curriculum Framework Syllabus Grades 7,8 \& 9 .

Mauritius Institute of Education (MIE) (2020) Mid-term Evaluation of the Extended Programme (2018-2019).

Meirink JA, Meijer PC, Verloop N and Bergen TC (2009) Understanding teacher learning in secondary education: The relations of teacher activities to changed beliefs about teaching and learning. Teaching and teacher education 25(1): 89-100.

Mills M, Baroutsis A, Mcgregor G, Te Riele K and Hayes D (2015) Alternative education and social justice: Considering issues of affective and contributive justice. Critical Studies in Education, 57(1): 100-115.

Mills M, Renshaw P and Zipin L (2013) Alternative education provision: A dumping ground for 'wasted lives' or a challenge to the mainstream? Social Alternatives 32(2): 13-18.

Ministry of Education and Human Resources (MoEHR) (2006a) Empowering the Nation's Children - Towards a Quality Curriculum.

Ministry of Education \& Human Resources (MoEHR) (2006b) Special education needs and inclusive education in Mauritius: The policy and strategy document.

Ministry of Education and Human Resources (MoEHR) (2011) New Strategy for Prevocational Education.

Ministry of Education and Human Resources, Tertiary Education and Scientific Research (MoEHRTESR) (2016a) Inspiring Every Child: Nine-Year Schooling. Reduit: Open University of Mauritius.

Ministry of Education and Human Resources, Tertiary Education and Scientific Research (MoEHRTESR) (2016b) Report on Screening Diagnosis and Progress Monitoring. Prevocational Education Unit.

Ministry of Education and Human Resources, Tertiary Education and Scientific Research (MoEHRTESR) (2017) The four-year extended programme.

National Human Rights Commission (NHRC) Mauritius (2007) Annual Report for the Year 2007. 
Organisation for Economic Co-operation and Development (OECD) (2012) Equity and quality in education: Supporting disadvantaged students and schools. Paris: OECD Publishing.

Pintrich PR and Schunk DH (2002) Motivation in education: Theory, research, and applications. Upper Saddle River, NJ: Merrill Prentice Hall.

Popham WJ (1999) Why standardized tests don't measure educational quality. Educational Leadership 56(6): 8-15.

Popham WJ (2000) Modern educational measurement: Practical guidelines for educational leaders. Boston: Allyn \& Bacon.

Rajah-Carrim A (2007) Mauritian Creole and Language Attitudes in the Education System of Multiethnic and Multilingual Mauritius. Journal of Multilingual and Multicultural Development 28(1): 51-71.

Rawls J (1971) A Theory of Justice. London: Harvard University Press.

Reese M, Gordon SP and Price LR (2004). Teachers' perceptions of high-stakes testing. Journal of School Leadership 14(5): 464-496.

Reiss M and White J (2013) An aims-based curriculum: The significance of human flourishing for schools. London: loE Press.

Reiss $M$ and White J (2014) An aims-based curriculum illustrated by the teaching of science in schools. Curriculum Journal 25(1): 76-89.

Sayer A (2009) Contributive justice and meaningful work. Res Publica 15(1): 1-16.

Sayer A (2011) Habitus, work and contributive justice. Sociology 45(1): 7-21.

Smith M (1991) Put to the Test: The Effects of External Testing on Teachers. Educational Researcher 20(5): 8-11.

Smyth J, Mclnerney P and Fish T (2013) Re-engagement to where? Low SES students in alternative-education programmes on the path to low-status destinations? Research in Post-Compulsory Education 18(1-2): 194-207.

Statistics Mauritius (SM) (2020) Education Statistics 2020.

Thomson P and Russell L (2007) Mapping the alternatives to permanent exclusion. New York: Joseph Rowntree Foundation.

United Nations General Assembly (UNGA) (2015) Transforming our world: the 2030 Agenda for Sustainable Development. Report no. A/RES/70/1.

Vygotsky LS (1962) Thought and Language. Cambridge, MA: MIT Press.

Wölfel $\mathrm{O}$ and Heineck G (2012) Parental risk attitudes and children's secondary school track choice. Economics of Education Review 31(5): 727-743.

Young M (2013) Overcoming the crisis in curriculum theory: A knowledge-based approach. Journal of Curriculum Studies 45(2): 101-118.

Young M (2016) What are schools for? In: Young M (ed) Curriculum and the specialisation of knowledge: studies in the sociology of education. London: Routledge. 